\title{
Prompt chlorophyll fluorescence as a tool for crop phenotyping: an example of barley landraces exposed to various abiotic stress factors
}

\author{
H.M. KALAJI ${ }^{*, * *}$, A. RASTOGI ${ }^{* * *, * * *,+}$, M. ŽIVČÁK ${ }^{* * * *}$, M. BRESTIC $^{* * * *}$, A. DASZKOWSKA-GOLEC ${ }^{\#}$, \\ K. SITKO ${ }^{\# \#, ~ K . Y . ~ A L S H A R A F A ~}{ }^{\# \#}$, R. LOTFI ${ }^{\S}$, P. STYPIŃSKI ${ }^{\S \S}$, I.A. SAMBORSKA ${ }^{\S \S \S}$, and M.D. CETNER ${ }^{\S \S \S}$ \\ Institute of Technology and Life Sciences (ITP), Falenty, Al. Hrabska 3, 05-090 Raszyn, Poland* \\ White Hill Company, Żurawia 71/3, 15-540 Biatystok, Poland ${ }^{* *}$ \\ Department of Meteorology, Poznan University of Life Sciences, Piatkowska 94, 60-649 Poznan, Poland ${ }^{* * *}$ \\ Department of Plant Physiology, Slovak University of Agriculture, A. Hlinku 2, 94976 Nitra, Slovak Republic ${ }^{* * * *}$ \\ Department of Genetics, Faculty of Biology and Environmental Protection, University of Silesia, Jagiellonska 28, 40-032 \\ Katowice, Poland ${ }^{\#}$ \\ Department of Plant Physiology, Faculty of Biology and Environmental Protection, University of Silesia, Jagiellonska 28 , \\ 40-032 Katowice, Poland ${ }^{\# \#}$ \\ Department of Biological Science, Faculty of Science, Mutah University, 61710 Mutah, Jordan ${ }^{\# \#}$ \\ Dryland Agricultural Research Institute, Agricultural Research Education \& Extension Organization, Maragheh, Iran ${ }^{\S}$ \\ Department of Agronomy, Warsaw University of Life Sciences, Nowoursynowska 159, 02-776 Warsaw, Poland $\$$ \\ Department of Plant Physiology, Faculty of Agriculture and Biology, Warsaw University of Life Science - SGGW, Ul. \\ Nowoursynowska 159, 02-776 Warsaw, Poland $\$ \$$
}

\begin{abstract}
The study examined photosynthetic efficiency of two barley landraces (cvs. Arabi Abiad and Arabi Aswad) through a prompt fluorescence technique under influence of 14 different abiotic stress factors. The difference in the behavior of photosynthetic parameters under the same stress factor in-between cv. Arabi Abiad and cv. Arabi Aswad indicated different mechanisms of tolerance and strategies for the conversion of light energy into chemical energy for both the landraces. This study confirmed the suitability of some chlorophyll fluorescence parameters as reliable biomarkers for screening the plants at the level of photosynthetic apparatus.
\end{abstract}

Additional key words: chlorophyll a fluorescence; JIP test; photosystem II.

\section{Introduction}

In this fast growing world, increasing productivity of the agricultural areas is a main objective of agronomical planners with a need of more productive and better adapted plant varieties to achieve it. Research on plant phenotyping is performed all around the world in order to make crop improvement efficient (Walter et al. 2015, Lootens et al.

2016). Plant phenotyping is a process which requires deep knowledge of plant physiology.

Photosynthesis is always considered to be a good measure of overall performance in plants. It is the only energy input in plants and thereby impacts all aspects of plant metabolism and physiology. Therefore, the assess-

Received 31 May 2017, accepted 25 August 2017, published as online-first 10 January 2018.

${ }^{+}$Corresponding author; e-mail: anshu.rastogi@up.poznan.pl

Abbreviations: ABS - absorption; $\mathrm{ABC} / \mathrm{RC}$ - absorption flux per one active reaction center; Area - total complimentary area between the fluorescence induction curve; Chl - chlorophyll; CS - cross section; DOT - days of treatment; ETC - electron transport chain; ET - electron transport; $F_{0}$ - fluorescence at time $0 ; F_{t}-$ fluorescence at time $t ; F_{v} / F_{0}$ - ratio of photochemical to nonphotochemical quantum efficiencies; HighPAR - high photosynthetic active radiation; HighT - high temperature; LowPAR - low photosynthetic active radiation; LowT- low temperature; $\mathrm{PI}(\mathrm{abs})$ - performance index on absorbance basis; $\mathrm{RC}$ - reaction center; $\mathrm{TR}_{0}$ - trapped energy flux; $\Psi_{0}$ - probability of an electron to reach the electron transport chain outside $\mathrm{Q}_{\mathrm{A}}$.

Acknowledgments: This work was supported by the research project of the Slovak Research and Development Agency under the project APVV-15-0721; and National Science Centre Poland, under the project UMO-2016/21/B/ST10/02271. AR thanks Slovak Academic Information Agency (SAIA) for providing National Scholarship for research in the year 2017. The present research was also financially supported by the grant of The National Centre for Research and Development (NCBR) - Ministry of Science and Higher Education, Poland. Agreement number POIR.01.01.01-00-1911/15-00 (Triffid - produkt przyszłości Klastra Obróbki Metali KKK. White Hill synergia kooperacji w obszarze B+R) and The financial Supports for Young Scientists (WULS-SGGW International Research Scholarship Fund: INT-270/2016- resolutions No. 64-2012/2013 and 42-2015/2016, Scholarship for one month travel abroad).

(C) The Author(s). This article is published with open access at link.springer.com 
ment of the photosynthetic phenomena and apparatus can play a very important role in plant phenotyping. Chlorophyll (Chl) fluorescence technique is a fast and economical method for the measurement of photosynthetic processes (Maxwell and Johnson 2000, Murchie and Lawson 2013). It may give a very large scale of data in a range of seconds which can provide a lot of information about a plant and ultimately help in its selection (Murchie and Lawson 2013). The measurement of photochemical process at PSII level and photosynthetic pigment contents gives a clear idea of a stress plant is going through (Kautsky and Hirsch 1931, Kalaji et al. 2016). In recent years, the measurement of Chl fluorescence has become a popular method for assessment of the impact of different stress factors on photosynthesis (Bolhàr-Nordenkampf and Öquist 1993, Schreiber et al. 1994, Maxwell and Johnson 2000, Strasser et al. 2000, Fracheboud and Leipner 2003, Kuckenberg et al. 2009, Dai et al. 2009).

Analysis of Chl fluorescence parameters can be used as a precise tool to test a direct response of adverse environmental conditions on photosynthesis and therefore the indirect assessment of their impact on plants (Kuckenberg et al. 2009). Chl fluorescence techniques have been used to study precisely effects of various stress factors, such as high and low temperature (Mathur et al. 2011), quality and intensity of radiation, water stress, salinity (Mehta et al. 2010), herbicides as inhibitors of photosynthesis, heavy metals (Mathur et al. 2016), particulate pollution (Tomar and Jajoo 2014), soil gas, and phytotoxic materials on plants and in atmosphere (Fracheboud and Leipner 2003, Dai et al. 2009). The test can be performed both on individual plants (including transgenic), or entire ecosystems in order to evaluate a tolerance for individual or various stress factors (Bolhàr-Nordenkampf and Öquist 1993, Schreiber et al. 1994, Strasser et al. 2000, Maxwell and Johnson 2000, Kalaji et al. 2016). Measurement of Chl fluorescence allows to detect stress response before we notice visible signs (wilting, necrosis, chlorosis) or before

\section{Materials and methods}

Plant material and growth conditions: Two landraces of barley (Hordeum vulgare L.) seedlings cvs. Arabi Abiad (Abiad) and Arabi Aswad (Aswad) were provided by the International Centre for Agricultural Research in the Dry Areas (ICARDA) of Aleppo in Syria.

The barley grains were placed in Petri dishes and germinated in the dark for $72 \mathrm{~h}$. Subsequently, seedlings were transferred to glass containers of $1 \mathrm{dm}^{3}$ containing modified Hoagland nutrient solution (Hoagland and Arnon 1950). The plants were placed in a greenhouse under the average temperature of $26^{\circ} \mathrm{C}$ and $18^{\circ} \mathrm{C}$ for day and night, respectively, the relative humidity was between $50-60 \%$, the photoperiod for the day/night cycle was $16 / 8 \mathrm{~h}$, and the maximum PAR was about $1,400 \mu \mathrm{mol}$ (photon) $\mathrm{m}^{-2} \mathrm{~s}^{-1}$ supplied by a sodium lamp (Philips High Pressure Sodium $600 \mathrm{~W} / 230 \mathrm{~V}, 90000 \mathrm{~lm}$, Gavita, Norway). After $11 \mathrm{~d}$ of it might be detected by other methods, such as measurements of gas exchange or changes in Chl contents (Devi et al. 1996, Roschina and Melnikowa 1996, Kalaji and Pietkiewicz 2004, Kalaji and Guo 2008, TsimilliMichael and Strasser 2008, Kuckenberg et al. 2009).

The relationship between light-phase reactions of photosynthesis and Chl fluorescence from PSII can be analyzed using a modern test JIP (OJIP) used for detailed analysis of the Chl fluorescence signals. The JIP test is useful for obtaining detailed information about the structure and function of the photosynthetic apparatus (mainly of PSII) (Strasser et al. 2004). Parts of the calculated parameters within the JIP test is related to energy fluxes for absorption (ABS), trapped energy flux $\left(\mathrm{TR}_{0}\right)$, and electron transport $(\mathrm{ET})$ per reaction center $(\mathrm{RC})$ or measured area of samples, called a cross section (CS).

Barley (Hordeum vulgare L.) belongs to the oldest known crops cultivated in the Eastern Mediterranean region. The cultivation of barley is spreading around the world, and the dynamic environment is also affecting the plant (Kang et al. 2009). Therefore, it is important for a crop manager to understand different factors affecting the photosynthetic activity and yield of this crop. Barley is also known to be tolerant to drought, salinity, and other biotic/abiotic stress factors, therefore, it is considered as a model organism in stress biology research (Gürel et al. 2016). Cultivar Arabi Aswad (Aswad) and cv. Arabi Abiad (Abiad) are two of the important landraces of barley cultivated in the Mediterranean region and therefore, they are important cultivars for research. In previous studies, the effects of salt, temperature, radiations, and heavy metals were assessed on these cultivars (Kalaji and Łoboda 2007, Kalaji et al. 2011a,b; 2012). In this study, we compared the effects of 14 abiotic stress factors on Aswad and Abiad to find out a pattern in photosynthetic properties under different stress factors, which can be used for the phenotyping of the plants.

growth (i.e., $14 \mathrm{~d}$ after the germination), the barley seedlings were treated with 14 different abiotic stresses To set up treatment values for different abiotic stress factors, a pilot study was performed (with the exception of mineral deficiency), and the value for a treatment was selected at the point, where the stress factor resulted in the reduction of approximately 50 percent of the seedling growth after $14 \mathrm{~d}$ of germination (see text table below).

Measurement and data analysis: The measurements were performed after 1 and $7 \mathrm{~d}$ of treatment (DOT) to compare the stress response and to observe the stress severity. Chl $a$ fluorescence measurement was performed at the middle region of mature leaves using the plant efficiency analyzer (Handy PEA, Hansatech Instrument Ltd., King's Lynn, Norfolk, England). Before measurements, barley 
The values for abiotic stress factors applied on barley seedlings (the value was obtained through the pilot study showing at least $50 \%$ decrease in plant growth).

\begin{tabular}{|c|c|c|}
\hline \multicolumn{2}{|l|}{ Abiotic stress factor } & \multirow{2}{*}{$\begin{array}{l}\text { Value of stress applied } \\
\text { PPFD of } 200 \mu \mathrm{mol} \mathrm{m}{ }^{-2} \mathrm{~s}^{-1}\end{array}$} \\
\hline Light & Low PAR & \\
\hline & High PAR & PPFD of $1,800 \mu \mathrm{mol} \mathrm{m}{ }^{-2} \mathrm{~s}^{-1}$ \\
\hline \multirow[t]{2}{*}{ Temperature } & Low & Average temperature (day/night) $10 / 6^{\circ} \mathrm{C}$ \\
\hline & High & Average temperature (day/night) $38 / 20^{\circ} \mathrm{C}$ \\
\hline \multirow[t]{2}{*}{ Heavy metals } & Cadmium & $\mathrm{CdCl}_{2}$ (concentration $25 \mu \mathrm{M}$ ) \\
\hline & Lead & $\mathrm{Pb}\left(\mathrm{NO}_{3}\right)_{2}$ (concentration $\left.50 \mu \mathrm{M}\right)$ \\
\hline Salt & $\mathrm{NaCl}$ & $120 \mathrm{mM}$ \\
\hline \multirow{7}{*}{$\begin{array}{l}\text { Deficiency of } \\
\text { macronutrients and } \\
\text { micronutrients }\end{array}$} & Nitrogen & Complete growth medium $-\mathrm{N}$ \\
\hline & Phosphorus & Complete growth medium $-\mathrm{P}$ \\
\hline & Potassium & Complete growth medium $-\mathrm{K}$ \\
\hline & Sulfur & Complete growth medium $-\mathrm{S}$ \\
\hline & Calcium & Complete growth medium $-\mathrm{Ca}$ \\
\hline & Magnesium & Complete growth medium $-\mathrm{Mg}$ \\
\hline & Iron & Complete growth medium $-\mathrm{Fe}$ \\
\hline
\end{tabular}

seedlings were kept in darkness for 45-60 min at room temperature. A detailed analysis of the measured signals of Chl fluorescence was conducted using the JIP test developed in the Laboratory of Bioenergetics of the University of Geneva in Switzerland, using Biolyzer version 3.0.6 software. For statistical relevance, three

\section{Results}

Transient fluorescence curve was analyzed in order to show the overall impact of abiotic stress factors on the plant. The five characteristic and important parameters of transient fluorescence curve, differing in their functional meaning, were used for the analyses here to represent the PSII behavior affected by the stress factors (Table 1).

Transient fluorescence curves: Transient fluorescence curve (the OJIP curve) for 14 abiotic stress factors on barley landraces were drawn for two time intervals of 1 and 7 DOT. In order to visualize better the influence of different abiotic stress factors on barley landraces, the curves were plotted as the ratio of relative fluorescence at time $t\left(F_{t}\right)$ to relative fluorescence at time $0\left(F_{0}\right)$. In order to make the figure clearer, the curves for individual stresses were divided into two parts, each containing 8 curves (including control).

After 1 DOT, cv. Abiad showed almost a flat fluorescence curve for high temperature (HighT), and cadmium (Cd) stress, which indicated the response to Cd and HighT was quite fast and the stress had severe effects on the leaf photochemistry (Fig. 1A), whereas the low temperature (LowT) negatively influenced the I and $\mathrm{P}$ stage of the curve after 1 DOT (Fig. 1A). All other stress factors did not show any significant effect on $\mathrm{cv}$. Abiad after 1 DOT (Fig. 1A,B). For Cd stress, cv. Aswad showed an almost flat pattern similar to Abiad, whereas low photosynthetically active radiation (LowPAR) showed a significant deviation at $\mathrm{J}, \mathrm{I}$, and $\mathrm{P}$ points of the curve in Aswad even after 1 DOT (Fig. 1C). The pattern of the other curves for measurements were performed for each plant; a mean value was calculated and considered to be $100 \%$ for control and the other values were calculated from the mean values. All data were analyzed using Statistica 8.0 software (Statsoft Inc., Tulsa, OK, USA).

cv. Aswad was similar to control for all other applied stress factors after 1 DOT (Fig. 1C,D). The influence of different abiotic stress factors on the transient fluorescence curve of barley landraces was much more significant after 7 DOT in comparison to 1 DOT (Fig. 1). Apart of Cd and HighT, salinity $(\mathrm{NaCl})$ and high photosynthetically active radiation (HighPAR) also induced a severe effect on cv. Abiad, whereas the influences of lead $(\mathrm{Pb})$, LowT, and LowPAR were less severe in cv. Abiad after 7 DOT (Fig. $1 E$ ). In cv. Aswad, Cd, Pb, HighT, and LowPAR caused severe effects at 7 DOT (Fig. $1 G$ ). The influence of the deficiency of nutrients on both the landraces was prominent after 7 DOT (Fig. $1 F, H$ ). Deficiency of potassium $(\mathrm{K})$ caused severe inhibition of PSII photochemistry, and calcium $(\mathrm{Ca})$ deficiency caused also the significant deprivation of photosynthetic activity at the PSII level for both the barley landraces. The severe iron (Fe) and magnesium $(\mathrm{Mg})$ deficiency significantly affected the PSII photochemistry after 7 DOT in cv. Aswad (Fig. $1 F, H$ ). J-I and I-P bands were significantly different under nutrient deficiency after 7 DOT for both the landraces.

$\Psi_{0}$ : The parameter represents the probability that an electron $\left(\mathrm{e}^{-}\right)$trapped by PSII will reach the electron transport chain outside $\mathrm{Q}_{\mathrm{A}}{ }^{-}$(Strasser et al. 2000, Živčák et al. 2008). After $1 \mathrm{DOT}$ of $\mathrm{Pb}, \mathrm{K}$, and Fe treatment, cv. Aswad showed a significant deviation in $\Psi_{0}$ value (more than $15 \%$ ), whereas the value calculated for plants exposed to $\mathrm{Cd}$ was close to 0 , which corresponded to the observation that the applied concentration of $\mathrm{Cd}$ was lethal 


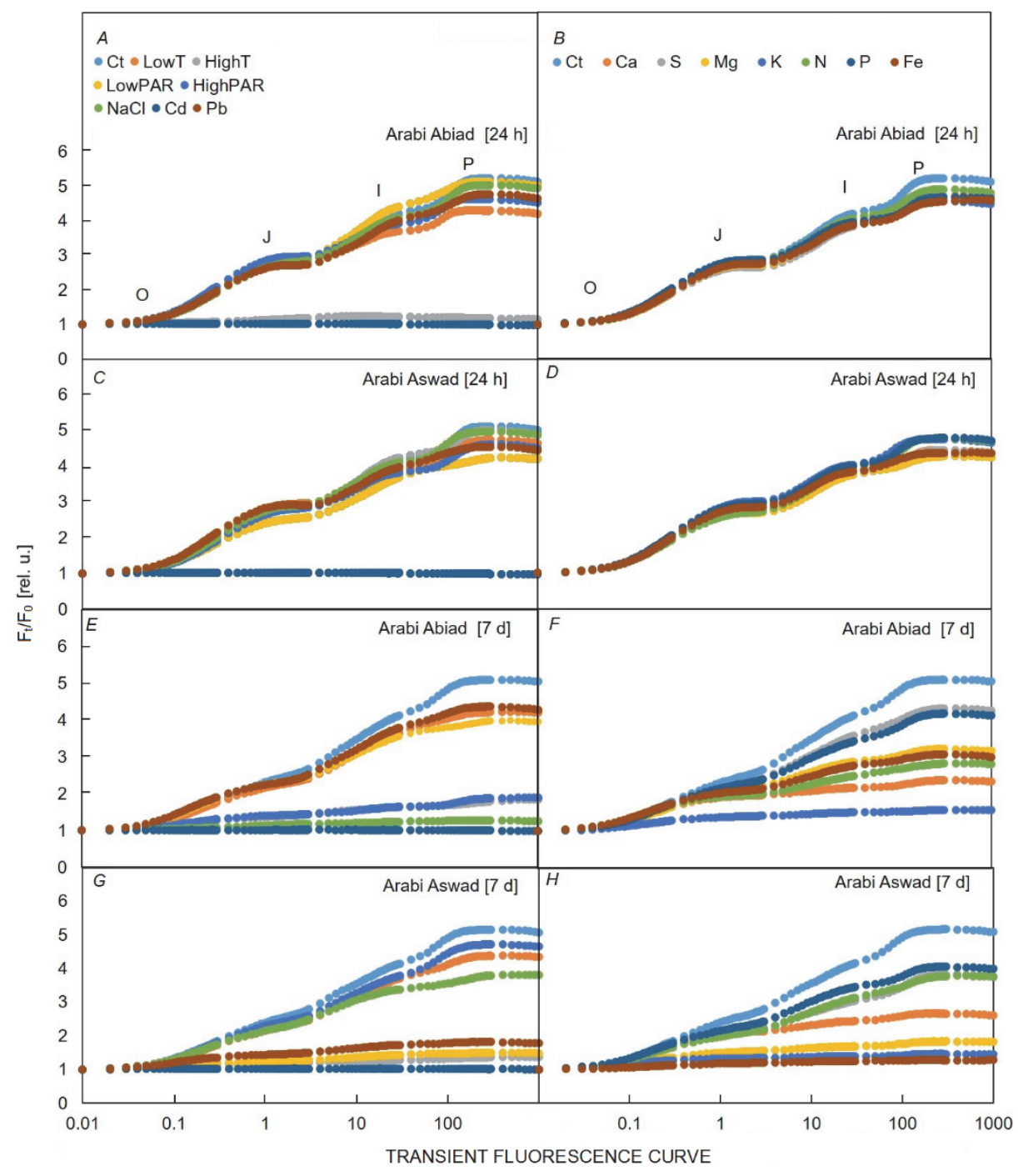

Fig. 1. Effect of different abiotic stress factors on fluorescence induction curves in barley. It represents the transient chlorophyll $a$ fluorescence induction curves of two Syrian landraces (cvs. Arabi Abiad and Arabi Aswad) after 1 and $7 \mathrm{~d}$ of various stresses application. $A, B, E$, and $F$ represent cv. Arabi Abiad after 1 and $7 \mathrm{~d}$ of stress application, whereas $C, D, G$, and $H$ represent cv. Arabi Aswad after 1 and $7 \mathrm{~d}$ of stress application. Ct represent the fluorescence induction curves of control, whereas LowT, HighT, LowPAR, High PAR, $\mathrm{NaCl}, \mathrm{Cd}, \mathrm{Pb}, \mathrm{Ca}, \mathrm{S}, \mathrm{Mg}, \mathrm{K}, \mathrm{N}, \mathrm{P}$, and $\mathrm{Fe}$ represent fluorescence induction curves under different stress factors.

for the plant and the response was fast (Table 1). In cv. Abiad, Hight $(62 \%)$ and LowT $(72.6 \%)$ showed a significant influence on $\Psi_{0}$ value, whereas HighPAR and $\mathrm{K}$ were also observed to show a significant deviation from the normal value within a day (Table 1). On 7 DOT, the influence of $\mathrm{Ca}, \mathrm{K}, \mathrm{Mg}$, and Fe deficiency on $\Psi_{0}$ was very high ( $>40 \%)$, whereas HighT, LowPAR, and $\mathrm{Pb}$ also showed a significant influence in cv. Aswad (Table 2). Salinity stress along with $\mathrm{Ca}$ and $\mathrm{K}$ deficiency showed a very significant decrease in the value of $\Psi_{0}$ in cv. Abiad, whereas $\mathrm{Fe}, \mathrm{N}$, and $\mathrm{Mg}$ were also observed to influence the value of $\Psi_{0}$ (Table 1$)$.

Area is the area above $\mathrm{Chl}$ fluorescence curve between $\mathrm{F}_{0}$ and $\mathrm{F}_{\mathrm{m}}$, i.e. the total complementary area between the fluorescence induction curve. It represents the pool of electron transporters in the electron transport chain (Strasser et al. 2000). After 1 DOT in cv. Aswad, stress factors, such as LowT, HighT, HighPAR, and N, did not cause a significant variation, whereas all other stress factors were observed to influence significantly the Area (Table 1). The deviation in the Area of cv. Abiad was observed to be less than $15 \%$ under $\mathrm{NaCl}, \mathrm{S}, \mathrm{N}$, and $\mathrm{Fe}$ stress in a day time (Table 1). In 7 DOT interval, the influence of stress factors was significant on the Area in cv. Aswad except for LowT, HighPAR, S, and P, whereas cv. Abiad showed a significant variation in for all the stresses in comparison with control (Table 2).

ABS/RC: It represents the absorption flux per one active reaction center (RC), a ratio of active to inactive $\mathrm{RCs}$ (Strasser et al. 2000). The value for ABS/RC was observed 
Table 1. Five important chlorophyll fluorescence parameters of two barley cultivars (cv. Arabi Aswad and Arabi Abiad) after $1 \mathrm{~d}(24 \mathrm{~h})$ of exposure to different abiotic stress factors (data are shown as \% of control). Data are presented as mean from at least three sets of different measurement (according to Duncan's multiple range test $p<0.05$ ).

\begin{tabular}{|c|c|c|c|c|c|c|c|c|c|c|}
\hline \multicolumn{6}{|c|}{ cv. Arabi Aswad } & \multicolumn{5}{|c|}{ cv. Arabi Abiad } \\
\hline Stress & $\Psi_{0}$ & Area & $\mathrm{ABS} / \mathrm{RC}$ & $\mathrm{F}_{\mathrm{v}} / \mathrm{F}_{0}$ & $\mathrm{PI}(\mathrm{abs})$ & $\Psi_{0}$ & Area & $\mathrm{ABS} / \mathrm{RC}$ & $\mathrm{F}_{\mathrm{v}} / \mathrm{F}_{0}$ & $\mathrm{PI}(\mathrm{abs})$ \\
\hline Low temp. & $86.01^{* *}$ & $96.09^{*}$ & $100.62^{*}$ & $90.01^{*}$ & $65.41^{* *}$ & $72.62^{* *}$ & $60.77^{* *}$ & $110.10^{* *}$ & $75.85^{* *}$ & $36.72^{* *}$ \\
\hline High temp. & $99.9^{*}$ & $98.34^{*}$ & $99.47^{*}$ & $97.95^{*}$ & $94.59^{*}$ & $61.99^{* *}$ & $0.63^{* *}$ & $341.58^{*}$ & $5.58^{* *}$ & $0.68^{* *}$ \\
\hline Low PAR & $95.38^{* *}$ & $69.95^{* *}$ & $110.45^{* *}$ & $78.04^{*}$ & $63.81^{* *}$ & $96.22^{*}$ & $71.97^{*}$ & $104.97^{* *}$ & 96.40 & $84.48^{*}$ \\
\hline High PAR & $90.29^{*}$ & $94.83^{*}$ & $100.65^{*}$ & $88.04^{*}$ & $70.21^{* *}$ & $81.25^{* *}$ & $63.99^{* *}$ & $110.17^{*}$ & $83.33^{*}$ & $49.33^{* *}$ \\
\hline $\mathrm{NaCl}$ & $94.85^{* *}$ & $85.25^{*}$ & $103.18^{* *}$ & $95.79^{*}$ & $82.68^{* *}$ & $98.53^{*}$ & $98.82^{*}$ & $101.03^{*}$ & $94.87^{*}$ & $91.19^{*}$ \\
\hline$+\mathrm{Cd}$ & $0.00^{* *}$ & $0.01^{* *}$ & $13,702^{* * *}$ & $0.14^{* *}$ & $0.00^{* *}$ & $0.00^{* *}$ & $0.01^{* *}$ & $20347^{* * *}$ & $0.15^{* *}$ & $0.00^{* *}$ \\
\hline$+\mathrm{Pb}$ & $82.55^{* *}$ & $54.85^{* *}$ & $115.82^{*}$ & $83.11^{*}$ & $48.51^{* *}$ & $96.47^{* *}$ & $76.30^{* *}$ & $109.42^{* *}$ & 87.99 & $74.44^{* *}$ \\
\hline$-\mathrm{Ca}$ & $87.24^{* *}$ & $65.94^{* *}$ & $109.89^{*}$ & $83.22^{* *}$ & $56.55^{* *}$ & $96.03^{* *}$ & $84.85^{*}$ & $105.92^{* *}$ & $88.06^{*}$ & $76.01^{*}$ \\
\hline$-S$ & $85.53^{* *}$ & $70.45^{* *}$ & $107.54^{*}$ & $83.08^{*}$ & $55.65^{* *}$ & $96.38^{*}$ & $87.80^{*}$ & $107.80^{*}$ & $84.38^{* *}$ & $72.19^{* *}$ \\
\hline$-\mathrm{Mg}$ & $87.11^{* *}$ & $61.87^{* *}$ & $112.28^{* *}$ & $78.16^{* *}$ & $52.20^{* *}$ & $92.51^{* *}$ & $84.29^{*}$ & $106.51^{* *}$ & $84.93^{*}$ & $66.90^{* *}$ \\
\hline$-K$ & $84.04^{*}$ & $64.14^{* *}$ & $102.28^{*}$ & $90.64^{*}$ & $62.08^{* *}$ & $84.55^{*}$ & $72.21^{* *}$ & $110.23^{*}$ & $82.39^{*}$ & $52.67^{* *}$ \\
\hline$-\mathrm{N}$ & $100.00^{*}$ & $89.20^{*}$ & $106.09^{* *}$ & $91.42^{*}$ & $86.27^{*}$ & $93.21^{* *}$ & $87.91^{*}$ & $102.88^{* *}$ & $91.14^{* *}$ & $76.10^{* *}$ \\
\hline$-\mathrm{P}$ & $87.64^{* *}$ & $78.37^{* *}$ & $105.23^{*}$ & $90.37^{*}$ & $65.11^{* *}$ & $87.57^{* *}$ & $81.72^{*}$ & $110.04^{* *}$ & $85.12^{*}$ & $58.17^{* *}$ \\
\hline$-\mathrm{Fe}$ & $81.52^{* *}$ & $53.41^{* *}$ & $106.70^{*}$ & $81.49^{* *}$ & $50.27^{* *}$ & $90.99^{*}$ & $87.77^{*}$ & $106.49^{*}$ & $83.90^{* *}$ & $64.28^{* *}$ \\
\hline
\end{tabular}

Table 2. Five important chlorophyll fluorescence parameters of two barley cultivars (cv. Arabi Aswad and Arabi Abiad) after $7 \mathrm{~d}$ of exposure to different abiotic stress factors (data are shown as \% of control). Data are presented as mean from at least three sets of different measurement (according to Duncan's multiple range test $p<0.05$ ).

\begin{tabular}{|c|c|c|c|c|c|c|c|c|c|c|}
\hline \multicolumn{6}{|c|}{ cv. Arabi Aswad } & \multicolumn{5}{|c|}{ cv. Arabi Abiad } \\
\hline Stress & $\Psi_{0}$ & Area & $\mathrm{ABS} / \mathrm{RC}$ & $\mathrm{F}_{\mathrm{v}} / \mathrm{F}_{0}$ & PI(abs) & $\Psi_{0}$ & Area & $\mathrm{ABS} / \mathrm{RC}$ & $\mathrm{F}_{\mathrm{v}} / \mathrm{F}_{0}$ & $\mathrm{PI}(\mathrm{abs})$ \\
\hline Low Temp. & $98.67^{* *}$ & $87.12^{*}$ & $108.16^{*}$ & $81.47^{*}$ & $73.18^{* *}$ & $93.83^{* *}$ & $69.28^{*}$ & $114.59^{*}$ & $78.86^{*}$ & $58.53^{*}$ \\
\hline HighTemp. & $84.12^{* *}$ & $15.04^{* *}$ & $387.79^{* *}$ & $9.13^{* *}$ & $1.57^{* *}$ & $84.86^{* *}$ & $30.74^{* *}$ & $222.41^{* *}$ & $18.98^{* *}$ & $5.78^{* *}$ \\
\hline Low PAR & $75.85^{* *}$ & $17.34^{* *}$ & $311.24^{*}$ & $12.23^{* *}$ & $2.12^{* *}$ & $85.95^{* *}$ & $67.96^{*}$ & $127.05^{*}$ & $72.20^{* *}$ & $39.51^{*}$ \\
\hline High PAR & $98.43^{*}$ & $92.51^{*}$ & $106.83^{* *}$ & $88.92^{*}$ & $80.62^{*}$ & $84.77^{*}$ & $42.38^{* *}$ & $229.66^{* *}$ & $20.71^{*}$ & $6.09^{* *}$ \\
\hline $\mathrm{NaCl}$ & $86.10^{* *}$ & $70.16^{* *}$ & $116.76^{* *}$ & $66.53^{* *}$ & $40.19^{* *}$ & $63.44^{* *}$ & $8.63^{* *}$ & $372.68^{*}$ & $5.95^{* *}$ & $0.61^{* *}$ \\
\hline$+\mathrm{Cd}$ & 0 & 0 & $2,897^{* * *}$ & 0.31 & 0 & $78.09^{* *}$ & $0.01^{*}$ & $20570^{* * *}$ & $0.16^{* *}$ & 0 \\
\hline$+\mathrm{Pb}$ & $73.26^{* *}$ & $18.63^{* *}$ & $263.80^{* *}$ & $18.18^{* *}$ & $3.49^{* *}$ & $94.28^{*}$ & $68.79^{* *}$ & $128.59^{*}$ & $81.08^{*}$ & $54.23^{* *}$ \\
\hline$-\mathrm{Ca}$ & $53.28^{*}$ & $13.67^{* *}$ & $163.02^{*}$ & $39.08^{* *}$ & $7.02^{* *}$ & $47.78^{* *}$ & $29.70^{* *}$ & $176.64^{*}$ & $32.69^{* *}$ & $4.70^{* *}$ \\
\hline$-S$ & $99.33^{*}$ & $85.82^{*}$ & $128.88^{*}$ & $65.76^{* *}$ & $50.63^{* *}$ & $96.59^{*}$ & $84.32^{*}$ & $109.78^{*}$ & $81.03^{*}$ & $67.43^{*}$ \\
\hline$-\mathrm{Mg}$ & $60.06^{* *}$ & $13.23^{* *}$ & $224.91^{* *}$ & $20.16^{* *}$ & $3.20^{* *}$ & $78.12^{* *}$ & $43.12^{* *}$ & $128.34^{* *}$ & $53.80^{*}$ & $23.96^{*}$ \\
\hline$-K$ & $48.36^{* *}$ & $7.43^{* *}$ & $405.80^{* *}$ & $9.70^{* *}$ & $0.62^{* *}$ & $49.48^{* *}$ & $16.62^{* *}$ & $293.11^{* *}$ & $13.12^{* *}$ & $1.20^{* *}$ \\
\hline$-\mathrm{N}$ & $99.42^{*}$ & $85.19^{* *}$ & $124.85^{*}$ & $65.36^{* *}$ & $51.69^{* *}$ & $73.77^{* *}$ & $52.38^{*}$ & $167.75^{* *}$ & $42.87^{* *}$ & $13.11^{* *}$ \\
\hline$-P$ & $93.58^{*}$ & $74.10^{* *}$ & $120.94^{*}$ & $71.47^{* *}$ & $50.44^{* *}$ & $93.50^{*}$ & $84.70^{*}$ & $114.68^{*}$ & $77.27^{*}$ & $56.83^{*}$ \\
\hline$-\mathrm{Fe}$ & $57.11^{* *}$ & $4.12^{* *}$ & $441.42^{* *}$ & $6.88^{* *}$ & $0.50^{* *}$ & $75.11^{*}$ & $43.29^{*}$ & $150.29^{*}$ & $48.71^{* *}$ & $17.16^{* *}$ \\
\hline
\end{tabular}

to be almost stable after 1 DOT except for $\mathrm{Cd}$ in both the landraces and HighT in cv. Abiad (Table 1). All the tested stress factors except lowT, HighPAR, and $\mathrm{NaCl}$ for $\mathrm{cv}$. Aswad and LowT, S, and P for cv. Abiad, were observed to significantly influence the $\mathrm{ABS} / \mathrm{RC}$ after 7 DOT (Table 2). The value of $\mathrm{ABS} / \mathrm{RC}$ was more than 3 times higher for HighT, LowPAR, Cd, P, and Fe in cv. Aswad, whereas in cv. Aswad it was 3 times higher for $\mathrm{NaCl}$, and P (Table 2).

$\mathbf{F}_{\mathbf{v}} / \mathbf{F}_{\mathbf{0}}$ : The ratio of photochemical to nonphotochemical quantum efficiencies, $\mathrm{F}_{\mathrm{v}} / \mathrm{F}_{0}$, was observed to be more than $20 \%$ lesser for LowPAR, Cd, and Mg after 1 DOT in cv. Aswad, whereas in cv. Abiad, more than 20\% variation was observed for LowT, HighT, and Cd (Table 1). After 7 DOT, the deviation in $\mathrm{F}_{\mathrm{v}} / \mathrm{F}_{0}$ was observed to be more prominent except for LowT and HighPAR in cv. Aswad, and $\mathrm{Pb}$ and $\mathrm{S}$ in $\mathrm{cv}$. Abiad (Table 2).

Performance index on absorbance basis [PI(abs)]: $\mathrm{PI}(\mathrm{abs})$ is an integrative parameter, which consider different phenomena related to PSII photochemical activity (Merz et al. 1996, Živčák et al. 2008). A very significant decrease in PI(abs) value was observed for cv. Aswad for different stress factor except for HighT, $\mathrm{NaCl}$, and $\mathrm{N}$ after 1 DOT (text table). In cv. Abiad, less significant differences for PI(abs) were observed under LowPAR and $\mathrm{NaCl}$ stress conditions, whereas all other factors were influencing PI(abs) significantly (Table 1). After 7 DOT, the values of PI(abs) were observed to vary significantly under almost all conditions for both the landraces (Table 2). 


\section{Discussion}

The study was performed to verify the importance of prompt fluorescence technique for plant phenotyping. In the chloroplast, there are two main target sites for biotic and abiotic stress: (1) electron transport chain (ETC), and (2) synthesis of Chl and carotenoids. The ETC with its electron carriers and enzymes is involved in phosphorylation and NADP photoreduction, whereas the synthesis of Chl and carotenoids can be related to LHC and antennae of the photosynthetic reaction centers (Dayan and Zaccaro 2012). The changes in both of these target sites can be detected and analyzed through the JIP-test and its parameters.

In transient fluorescence curve or OJIP curve, different parts indicate different phenomena of photosystems: the $\mathrm{O}-\mathrm{J}$ phase denotes gradual reduction of $\mathrm{Q}_{\mathrm{A}}$, the primary electron acceptor in PSII, the $\mathrm{J}-\mathrm{I}$ phase is responsible for Chl fluorescence quenching, which characterizes the water diffusion complex activity at PSII donor side, whereas I-P phase indicates the rate of reduction of ferredoxin and is taken as a measure of the relative abundance of PSI with respect to PSII (Oukarroum et al. 2007, Desotgiu et al. 2010, Cascio et al. 2010) or, alternatively, it is related to the relative size of the pools of final PSI electron acceptors (Tsimilli-Michael and Strasser 2008, Živčák et al. 2014). For most of the stress factors, the $\mathrm{O}-\mathrm{J}$ phases were observed to be similar in both the landraces after 1 DOT (except $\mathrm{Cd}$ in both landraces, and HighT in cv. Abiad) (Fig. $1 A-D$ ). After 7 DOT, the variation in transient fluorescence curve was much visible for different stress factors (Fig. 1). The improvement of the curve for HighT and LowT stress in cv. Abiad with time showed the activation of adaptive mechanism in the plant. Deficiency of nutrients for both the landraces showed a significant deviation in the curve with respect to time, which indicated that the plants tried to fulfill its needs by utilizing stored proteins and as the stored protein became depleted, the plant started showing an adverse response. The transient fluorescence curve gives an idea about the plant status which can be better understood by analyzing different parameters on which the curve is based. The effect and pattern of HighT stress on both landraces indicated that the avoidance mechanism of high temperature for cv. Abiad was weak in respect to cv. Aswad, but when the stress was applied continuously, both the plants showed a diminished photochemical activity of PSII. Improved photosynthetic parameters for cv. Abiad after 7 DOT of HighT stress indicated activation of plants adaptive mechanism.

Although the heat stress has the negative effects on PSI (Tiwari et al. 2008, Živčák et al. 2015) or other components of ETC, the effects of high temperature on PSII are the most prominent. It is well known that the oxygenevolving complex is one of the most sensitive components of PSII, which is reflected also at the level of OJIP kinetics (Srivastava et al. 1997, Mathur et al. 2011). The different PSII temperature tolerance of genotypes, which was observed in our experiment, is consistent with the results of field experiments in wheat (Brestic et al. 2012).

The photosynthetic parameters for LowT stress also showed an improvement in cv. Abiad with time. Therefore, it can be concluded that even if the avoidance mechanism for LowT and HighT is not sufficient for cv. Abiad, the adaptive mechanism starts functioning early when compared to cv. Aswad. The cultivar Abiad proved a better adaptability to LowPAR with time in comparison to $\mathrm{cv}$. Aswad, whereas the response for HighPAR was completely opposite in both landraces. It indicates the mechanism of adaptation for LowPAR and HighPAR is different for both the landraces. Salinity stress showed its influence on photosynthetic activities of the plant as a slow process, but influenced more cv. Abiad in comparison to cv. Aswad with time. This indicates that the resistance or activation of adaptive mechanism against $\mathrm{NaCl}$ stress in cv. Aswad is more efficient. Cadmium was found to be lethal for both the landraces even at a very low concentration. $\mathrm{Cd}$ is known to be accumulated in plants organs, preferentially in the chloroplasts, and disturbs the chloroplast function by inhibiting activities of enzymes in $\mathrm{Chl}$ biosynthesis and $\mathrm{CO}_{2}$ fixation (Krupa and Baszynski 1995, Siedlecka et al. 1997) or the aggregation of pigment-protein complexes of the photosystems (Horváth et al. 1996). Therefore, the results obtained indicate that the absorption and transport of Cd was very fast in both the landraces which led to the immediate impact on photosynthesis, and both the landraces lack any adaptive mechanism to tolerate the $\mathrm{Cd}$ stress. $\mathrm{Pb}$ is known to inhibit the enzymatic process in plants and therefore influence photosynthesis (Sharma and Dubey 2005). Cv. Aswad showed a higher sensitivity towards $\mathrm{Pb}$ stress as $\mathrm{PI}(\mathrm{abs})$ decreased to almost $50 \%$ within a day with further decreases to $3.5 \%$ in 7 DOT, whereas, in cv. Abiad, the PI(abs) decreased from $74.4 \%$ to $54.2 \%$ on 7 DOT. The observation indicates a better mechanism of adaptability for $\mathrm{Pb}$ stress in $\mathrm{cv}$. Abiad. $\mathrm{Ca}$ deficiency is known to influence the chloroplast integrity and therefore can influence the photosynthetic activity (Terry and Huston 1975). The observation indicated that both the landraces were showing a similar response to $\mathrm{Ca}$ and the adaptive mechanism were not efficient as the PI(abs) decreased around 5\% after 7 DOT for both the landraces. S deficiency is associated with a Chl content (Terry 1976), therefore, it is known to influence the photosynthetic activity. $\mathrm{S}$ is also a structure molecule and is the part of amino acids, cysteine, and methionine. Our observation indicates that $\mathrm{S}$ deficiency did not influence the photosynthetic activity at any large extent. The response may be due to the plants capability to survive for short time without $\mathrm{S}$, due to minimising the need of $\mathrm{S}$ for the necessary processes. The deficiency of $\mathrm{K}$ was observed to influence significantly the transient fluorescence curve for both the landraces as $\mathrm{K}^{+}$is needed to balance the electrical 
charge at the site of ATP production (Santelia and Lawson 2016). When plants are deficient in $K$, the rate of photosynthesis and the rate of ATP production are reduced, and all processes based on ATP are slowed down, therefore we observed a significant decrease in the transient curve and its parameters after $7 \mathrm{DOT} . \mathrm{Mg}$ is necessary for photophosphorylation and Chl synthesis along with other processes in plants (Surpin et al. 2002). Therefore, a decrease in $\mathrm{Mg}$ influences negatively the photosynthetic activity. $\mathrm{Cv}$. Abiad was observed to show a lower decrease in photosynthetic parameters compared to Aswad, which indicates the better use of available resources by cv. Abiad. Nitrogen is one of the most abundant element in plants and major component of proteins (Kaur et al. 2017), therefore, its deficiency influence photosynthesis negatively, which was evident from our observation. Compared to other stresses, the nitrogen deprivation did not affect severely the maximum photochemical efficiency, but the capacity of electron acceptors and electron transport beyond PSII is affected, which is reflected also in the decrease of performance index (Živčák et al. 2014). Cv. Aswad showed better photosynthetic parameters for $\mathrm{N}$ deficiency in respect to cv. Abiad after 7 DOT. The observation indicates more efficient mechanism to utilize nitrogen by cv. Aswad when compared to cv. Abiad. $\mathrm{P}$ is an essential part of photophosphorylation and is among one of the most important nutrients for plants, therefore $\mathrm{P}$ deficiency influence the photosynthetic process. The $\mathrm{P}$ deficiency was observed to slightly decrease photosynthetic parameters in both the cultivars, when compared after 1 and 7 DOT. The plant store $\mathrm{P}$ in several forms, which can be used when plants are facing $\mathrm{P}$ deficiency. The similar effect for both the cultivars indicate a similar mechanism of adaptation for $\mathrm{P}$ deficiency. Fe deficiency reduces the number of grana as well as granal and stromal lamellae per chloroplast (Spiller and Terry 1980), and diminishes the amount of electron carrier in ETC (Morales et al. 1991); therefore, Fe deficiency negatively influences the photosynthetic processes, which can be seen by a decrease in the value for photosynthetic parameters. The observation indicates cv. Aswad had a low capability to use the available Fe when compared to cv. Abiad.

The observation indicated that cv. Arabi Aswad was more tolerant towards HighPAR, HighT, LowT, $\mathrm{NaCl}$, and $\mathrm{N}$ deficiency when compared to cv. Arabi Abiad. However, the plants of cv. Arabi Abiad showed a higher tolerance to the presence of $\mathrm{Pb}$, deficiency of $\mathrm{K}, \mathrm{Mg}, \mathrm{S}, \mathrm{Fe}$, and $\mathrm{Ca}$ in comparison to $\mathrm{cv}$. Arabi Aswad. A similar response for both cultivars was observed in the presence of $\mathrm{Cd}$ and $\mathrm{P}$ deficiency. Therefore, prompt fluorescence measurement could give an idea about the plant's suitability to different abiotic stress factors. Among the discussed parameters, PI(abs) was observed to be most sensitive to the fluctuations in different conditions, as it represents the overall activity of PSII. The cultivars studied are known to originate from the same geographical area (Fertile Crescent in Syria), thus, they faced similar climatic challenges. The study indicates that, despite of faceing similar climatic conditions, the cultivars have developed a different mechanism to torelate different stress factors. Therefore, the study verified the use of prompt fluorescence analysis for plant phenotyping.

Open Access This article is distributed under the terms of the Creative Commons Attribution License which permits any use, distribution, and reproduction in any medium, provided the original author(s) and the source are credited.

\section{References}

Bolhàr-Nordenkampf H.R., Öquist G.: Chlorophyll fluorescence as a tool in photosynthesis research. - In: Hall D.O., Scurlock J.M.O., Bolhàr-Nordenkampf H. R. et al. (ed.): Photosynthesis and production in a changing environment: a field and laboratory manual. Pp. 193-206. Chapman \& Hall, London 1993.

Brestic M., Živčák M., Kalaji H.M. et al.: Photosystem II thermostability in situ: environmentally induced acclimation and genotype-specific reactions in Triticum aestivum L. - Plant Physiol Bioch. 57: 93-105, 2012.

Cascio C., Schaub M., Novak K. et al.: Foliar responses to ozone of Fagus sylvatica L. seedlings grown in shaded and in full sunlight conditions. - Environ. Exp. Bot. 68: 188-197, 2010.

Dai Y., Shen Z., Liu Y. et al.: Effects of shade treatments on the photosynthetic capacity, chlorophyll fluorescence, and chlorophyll content of Tetrastigma hemsleyanum Diels et Gilg. Environ. Exp. Bot. 65: 177-182, 2009.

Dayan F.E., Zaccaro M.L.M.: Chlorophyll fluorescence as a marker for herbicide mechanisms of action. - Pestic. Biochem. Phys. 102: 189-197, 2012.

Desotgiu R., Bussotti F., Faoro F. et al.: Early events in Populus hybrid and Fagus sylvatica leaves exposed to ozone. - Sci. World J. 10: 512-527, 2010.

Devi S.R., Prasad M.N.V.: Influence of ferulic acid on photo synthesis of maize: analysis of $\mathrm{CO}_{2}$ assimilation, electron transport activities, fluorescence emission and photophosphorylation. - Photosynthetica 32: 117-127, 1996.

Fracheboud Y., Leipner J.: The application of chlorophyll fluorescence to study light, temperature, and drought stress. In: De-Ell J.R., Toivonen P.M.A. (ed.): Practical Applications of Chlorophyll Fluorescence in Plant Biology. Pp. 125-150, Kluwer Acad. Publ. Dordrecht 2003.

Gürel F., Öztürk Z. N., Uçarli C., Rosellini D.: Barley genes as tools to confer abiotic stress tolerance in crops. - Front. Plant Sci. 7: 1137, 2016.

Hoagland D.R., Arnon D.I.: The Water-Culture Method for Growing Plants Without Soil, California. California Agricultural Experiment Station, Circular 347. Pp. 1-32. Univ. of California, Berkeley 1950.

Horváth G., Droppa M., Oravecz A. et al.: Formation of the photosynthetic apparatus during greening of cadmiumpoisoned barley leaves. - Planta 199: 238-243, 1996. 
Kalaji H.M., Bosa K., Kościelniak J., Hossain Z.: Chlorophyll a fluorescence - A useful tool for the early detection of temperature stress in spring barley (Hordeum vulgare L.). OMICS 15: 925-934, 2011a.

Kalaji H.M., Carpentier R., Allakhverdiev S.I., Bosa K.: Fluorescence parameters as early indicators of light stress in barley. - J. Photoch. Photobio. B 112: 1-6, 2012.

Kalaji H.M., Govindjee, Bosa K. et al.: Effects of salt stress on photosystem II efficiency and $\mathrm{CO}_{2}$ assimilation of two Syrian barley landraces. - Environ. Exp. Bot. 73: 64-72, 2011 b.

Kalaji H.M., Guo P.: Chlorophyll fluorescence: a useful tool in barley plant breeding programs. - In: Sánchez A., Gutiérrez S.J. (ed.): Photochemistry Research Progress. Pp. 439-463. Nova Sci. Publ. Inc., New York 2008.

Kalaji H.M., Jajoo A., Oukarroum A. et al.: Chlorophyll $a$ fluorescence as a tool to monitor physiological status of plants under abiotic stress conditions. - Acta Physiol. Plant. 38: 102, 2016.

Kalaji H.M., Łoboda T.: Photosystem II of barley seedlings under cadmium and lead stress. - Plant Soil Environ. 53: 511-516, 2007.

Kalaji H.M., Pietkiewicz S.: Some physiological indices to be exploited as a crucial tool in plant breeding. - Plant Breed. Seeds Sci. 49: 19-39, 2004.

Kang Y., Khan S., Ma X.: Climate change impacts on crop yield, crop water productivity and food security - A review. - Prog. Nat. Sci. 19: 1665-1674, 2009.

Kaur B., Kaur G., Asthir B.: Biochemical aspects of nitrogen use efficiency: An overview. - J. Plant Nutr. 40: 506-523, 2017.

Kautsky H., Hirsch A.: [New attempts to assimilate carbonic acid.] - Naturwissenschaften 19: 96, 1931. [In German]

Krupa Z., Baszynski T.: Some aspects of heavy metals toxicity towards photosynthetic apparatus - direct and indirect effects on light and dark reactions: a review. - Acta Physiol. Plant. 17: 177-190, 1995.

Kuckenberg J., Tartachnyk I., Noga G.: Temporal and spatial changes of chlorophyll fluorescence as a basis for early and precise detection of leaf rust and powdery mildew infections in wheat leaves. - Precis. Agric. 10: 34-44, 2009.

Lootens P., Ruttink T., Rohde A. et al.: High-throughput phenotyping of lateral expansion and regrowth of spaced Lolium perenne plants using on-field image analysis. - Plant Methods 12: 32, 2016.

Mathur S., Jajoo A., Mehta P., Bharti S.: Analysis of elevated temperature-induced inhibition of photosystem II using chlorophyll a fluorescence induction kinetics in wheat leaves (Triticum aestivum). - Plant Biol. 13: 1-6, 2011.

Mathur S., Kalaji H.M., Jajoo A.: Investigation of deleterious effects of chromium phytotoxicity and photosynthesis in wheat plant. - Photosynthetica 54: 185-192, 2016.

Maxwell K., Johnson N.G.: Chlorophyll fluorescence - a practical guide. - J. Exp. Bot. 51: 659-668, 2000.

Mehta P., Jajoo A., Mathur S., Bharti S.: Chlorophyll a fluorescence study revealing effects of high salt stress on Photosystem II in wheat leaves. - Plant Physiol. Bioch. 48: 1620, 2010.

Merz D., Geyer M., Moss D.A., Ache H.-J.: Chlorophyll fluorescence biosensor for the detection of herbicides. - Fresen J. Anal. Chem. 354: 299-305, 1996.

Morales F., Abadía A., Abadía J.: Chlorophyll fluorescence and photon yield of oxygen evolution in iron-deficient sugar beet (Beta vulgaris L.) leaves. - Plant Physiol. 97: 886-893, 1991.

Murchie E.H., Lawson T.: Chlorophyll fluorescence analysis: a guide to good practice and understanding some new applications. - J. Exp. Bot. 64: 3983-3998, 2013.

Oukarroum A., Madidi S.E., Schansker G., Strasser R.J.: Probing the responses of barley cultivars (Hordeum vulgare L.) by chlorophyll $a$ fluorescence OLKJIP under drought stress and re-watering. - Environ. Exp. Bot. 60: 438-446, 2007.

Roschina V., Melnikowa E.V.: Microspectrofluorometry: a new technique to study pollen allelopathy. - Allelopathy J. 3: 51-58, 1996.

Santelia D., Lawson T.: Rethinking guard cell metabolism. Plant Physiol. 172: 1371-1392, 2016.

Schreiber U., Bilger W., Neubauer C.: Chlorophyll fluorescence as a nonintrusive indicator for rapid assessment of in vivo photosynthesis. - In: Schulze E.D., Caldwell M.M. (ed.): Ecophysiology of Photosynthesis. Pp. 49-70. Springer, Berlin 1994.

Sharma P., Dubey R.: Lead toxicity in plants. - Braz. J. Plant Physiol. 17: 35-52, 2005.

Siedlecka A., Krupa Z., Samuelsson G. et al.: Primary carbon metabolism in Phaseolus vulgaris plants under $\mathrm{Cd} / \mathrm{Fe}$ interaction. - Plant Physiol. Bioch. 35: 951-957 1997.

Spiller S., Terry N.: Limiting factors in photosynthesis: II. Iron stress diminishes photochemical capacity by reducing the number of photosynthetic units. - Plant Physiol. 65: 121-125, 1980.

Srivastava A., Guisse B., Greppin H., Strasser R.J.: Regulation of antenna structure and electron transport in photosystem II of Pisum sativum under elevated temperature probed by the fast polyphasic chlorophyll a fluorescence transient: OKJIP. BBA-Bioenergetics 1320: 95-106, 1997.

Strasser R.J., Srivastava A., Tsimilli-Michael M.: The fluorescent transient as a tool to characterize and screen photosynthetic samples. - In: Yunus M., Pathre, U., Mohanty P. (ed.): Probing Photosynthesis: Mechanisms, Regulation and Adaptation. Pp. 445-483. Taylor and Francis, London 2000.

Strasser R.J., Tsimilli-Michael M., Dangre D., Rai M.: Biophysical phenomics reveals functional building blocks of plants system biology: acase study for evaluation of the impast of Mycorrhization with Piriformospora indica. - In: Varma A., Oelmüller R. (ed.): Advanced Techniques in Soil Biology. Pp. 319-338. Springer, Berlin 2004

Surpin M., Larkin R.M., Chory J.: Signal transduction between the chloroplast and the nucleus. - Plant Cell 14S: S327-S338, 2002.

Terry N., Huston R.P.: Effects of calcium on the photosynthesis of intact leaves and isolated chloroplasts of sugar beets. - Plant Physiol. 55: 923-927, 1975.

Terry N.: Effects of sulfur on the photosynthesis of intact leaves and isolated chloroplasts of sugar beets. - Plant Physiol. 57: 477-479, 1976

Tiwari A., Jajoo A., Bharti S.: Heat-induced changes in photosystem I activity as measured with different electron donors in isolated spinach thylakoid membranes. - Photoch. Photobio. Sci. 7: 485-491, 2008.

Tomar R.S., Jajoo A.: Fluoranthene, a polycyclic aromatic hydrocarbon, inhibits light as well as dark reactions of photosynthesis in wheat (Triticum aestivum). - Ecotoxicol. Environ. Safe. 109: 110-115, 2014.

Tsimilli-Michael M., Strasser R.J.: In vivo assessment of stress impact on plant's vitality: applications in detecting and evaluating the beneficial role of mycorrhization on host plants. - In: Varma A. (ed.): Mycorrhiza: State of the Art, Genetics and Molecular Biology, Eco-Function, Biotechnology, Eco- 
Physiology, Structure and Systematics ( $3^{\text {rd }}$ edition). Pp. 679703. Springer, Berlin - Heidelberg 2008.

Walter A., Liebisch F., Hund A.: Plant phenotyping: from bean weighing to image analysis. - Plant Methods 11: 14, 2015.

Živčák M., Brestic M., Kunderlikova K. et al.: Effect of photosystem I inactivation on chlorophyll a fluorescence induction in wheat leaves: does activity of photosystem I play any role in OJIP rise? - J. Photoch. Photobio. B 152: 318-324, 2015.
Živčák M., Breštič M., Olšovska K., Slamka P.: Performance index as a sensitive indicator of water stress in Triticum aestivum L. - Plant Soil Environ. 54: 133-139, 2008.

Živčák M., Olšovská K., Slamka P. et al.: Application of chlorophyll fluorescence performance indices to assess the wheat photosynthetic functions influenced by nitrogen deficiency. - Plant Soil Environ. 60: 210-215, 2014. 